Article

\title{
Efficient Gas Barrier and Antibacterial Properties of Poly(lactic acid) Nanocomposites: Functionalization with Phytic Acid-Cu(II) Loaded Layered Clay
}

\author{
Yongzhen Lei ${ }^{1}$, Long Mao ${ }^{1,2, *}$, Jin Yao ${ }^{1, *}$ and Zhihan $\mathrm{Li}^{1}$ \\ 1 Key Laboratory of Advanced Packaging Materials and Technology of Hunan Province, Hunan University of \\ Technology, Zhuzhou 412007, China; leiyz@hut.edu.cn (Y.L.); lizh@hut.edu.cn (Z.L.) \\ 2 Fujian Provincial Key Laboratory of Functional Materials and Applications, Xiamen University of \\ Technology, Xiamen 361024, China \\ * Correspondence: 2014113210@xmut.edu.cn (L.M.); yaojin@hut.edu.cn (J.Y.)
}

Received: 16 March 2020; Accepted: 23 April 2020; Published: 27 April 2020

\begin{abstract}
Poly(lactic acid) (PLA) represents one of the most promising and attractive bio-based polymers for green packaging. However, toughness, gas barrier and antibacterial properties of pure PLA films cannot compete with those of traditional petroleum-based active packaging plastics. To fill this gap, utilization of excellent chelating properties of phytic acid (PA), functionalized layered double hydroxides (LDHs@PA-Cu(II)) was firstly synthetized via facile deposition and chelation of one-step assembled PA-Cu(II) coordination compounds on the surface of layered clay. Furthermore, LDHs@PA-Cu(II)/PLA nanocomposites were prepared by blending LDHs@PA-Cu(II) and pure PLA via solution casting evaporation process. After adding only $1 \mathrm{wt} \% \mathrm{LDHs} @ \mathrm{PA}-\mathrm{Cu}(\mathrm{II})$, elongation at break and tensile strength increase by $53.0 \%$ and $18.9 \%$, respectively, and the oxygen relative permeability decreases by $28.0 \%$. Due to the strong interface interaction and heterogenous nucleation, the reinforcement effect of LDHs@PA-Cu(II) at low loadings is remarkable. Meanwhile, owing to the antibacterial activity of PA-Cu(II) coatings, the antibacterial rate (against Escherichia coli) of LDHs@PA-Cu(II) exceeds 99.99\%. Furthermore, the corresponding LDHs@PA-Cu(II)/PLA nanocomposites also show outstanding antibacterial properties, which will be a promising candidate for active packaging application.
\end{abstract}

Keywords: layered double hydroxides; phytic acid; antibacterial activity; polylactic acid; barrier properties

\section{Introduction}

In recent years, food safety concerns have given rise to the development and relevant applications of active packaging materials [1,2]. Active packaging can prolong the shelf life of food by improving the gas barrier, antibacterial and antioxidant properties of packaging materials [3,4]. Meanwhile, as a promising form of active packaging, antibacterial packaging is beneficial to food preservation, the reason is that active packaging can delay food spoilage through the deactivation or inhibiting the growth of various microorganisms [3]. Therefore, while trying to reduce the gas barrier properties of packaging materials, using appropriate antibacterial packaging technology is also an effective way to prolong the shelf life of food.

A majority of polymeric packaging materials are produced from non-renewable petroleum resources, and eventually become spontaneous and non-degradable waste [5]. It is strongly necessary to develop fully biodegradable polymeric packaging materials with excellent comprehensive performance to alleviate the dependence on petroleum-based polymer. Among all these biodegradable polymers, poly(lactic acid) (PLA) has attracted considerable attention in the recent decades due to its effective 
biodegradability and availability from renewable resources such as starch and corn [6]. PLA is considered as a valuable candidate to replace petroleum-based polymer in many fields (packaging, medicine and agriculture, etc.) because of its good optical, thermomechanical properties, and processability [3,7]. However, in the face of various packaging conditions, the gas barrier properties and antibacterial activity of pure PLA are difficult to meet the requirements of active packaging.

PLA based naonocomposites with improved properties have been studied extensively. Recently, layered clay with low cost, non-toxicity and human compatibility has received increasing attention in the blending modification of PLA. Considered as a natural barrier material, layered clay has an impermeable layered structure, which can prolong the permeation pathway of gas molecules in the composite film [8-10]. Among the layered clay, layered double hydroxides (LDHs) have the advantages of versatility, homogeneous structure, and large specific surface area as well as designable chemical composition [11,12]. However, previous studies about the properties of LDHs/PLA nanocomposites were mostly confined to thermal and mechanical properties, and little on the gas barrier properties and antibacterial activity. Gonçalves reported the investigation of intercalated CaAl-LDHs/PLA nanocomposites [13]. It was revealed that the thermal stability and UV barrier properties of PLA nanocomposites were higher than those of pure PLA. Katiyar reported that LDHs/PLA nanocomposites were prepared by in-situ polymerization of lactide dimer intercalated within LDHs [14]. However, the molecular weight of PLA was significantly decreased in the presence of LDHs. According to previous reports, both intercalation and in-situ polymerization of LDHs can improve the dispersion of LDHs in PLA matrix, but they may be complex and unstable modification processes. Surface organic coating is a very effective and convenient modification method, which can improve the interfacial adhesion between LDHs and polymer matrix. In the process of surface modification, antibacterial substances can also be loaded on the surface of LDHs, so as to realize multifunction of LDHs. Our research group has been committed to the application of surface functionalized LDHs to various polymers matrix [15-17]. We have reported that tannic acid-Fe(III) coated LDHs was firstly synthetized via deposition and chelation of tannic acid with ferric iron [15]. The results showed that elongation at break and oxygen barrier properties increased by $47 \%$ and $21 \%$ respectively at a low surface functionalized LDHs loading of $1 \mathrm{wt} \%$ in poly( $\varepsilon$-caprolactone) matrix. It indicates that the application of surface functionalized LDHs has great research potential in polymer matrix.

Phytic acid (PA) is a natural substance extracted from legume seeds, cereal grains and beans [18]. It has attracted more and more attention in food additives, antibacterial agents and metal corrosion-resistant in recent years because of its unique properties such as non-toxicity, low cost, good biocompatibility and environmental protection [19]. More importantly, PA consists of six phosphates groups attached symmetrically to a cyclohexanehexol ring which can interact with positively charged metal ions and biological molecules [20]. In this study, PA was applied to coat on the LDHs by complexing with antibacterial metal ions without the participation of organic solvent. Hence, as shown in Scheme 1, a green and facile way was proposed to utilize PA-Cu(II) coordination compounds to in-situ functionalize LDHs (LDHs@PA-Cu(II)) for the first time. The functional coordination compounds can promote the homogeneous dispersion of LDHs in PLA matrix, contributing to better interface compatibility and interaction between LDHs and PLA. LDHs@PA-Cu(II)/PLA nanocomposite films were fabricated by solution casting evaporation process. The purpose of the present study was to develop biodegradable PLA nanocomposite films with different addition of LDHs@PA-Cu(II) to evaluate microstructural, thermal, crystallization, mechanical, antibacterial, and gas barrier properties for active packaging applications. 


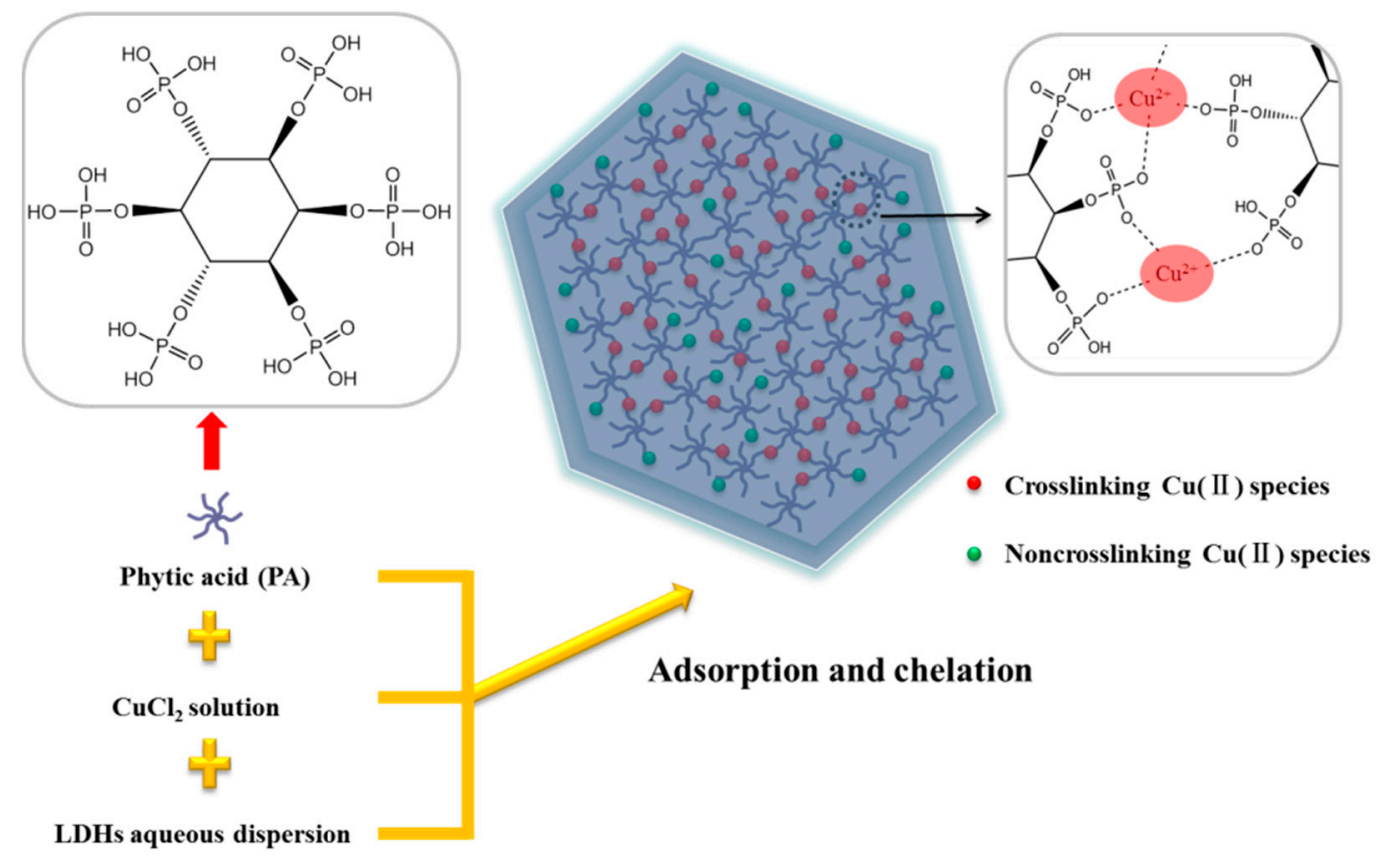

Scheme 1. A schematic illustration of the synthesis for LDHs@PA-Cu(II).

\section{Materials and Methods}

\subsection{Materials and Chemicals}

$\mathrm{MgAl}-\mathrm{CO}_{3}$ LDHs was synthesized by hydrothermal method according to previous report [17]. Phytic acid (PA) solution ( $70 \%$ in $\left.\mathrm{H}_{2} \mathrm{O}\right), \mathrm{CuCl}_{2} \cdot 2 \mathrm{H}_{2} \mathrm{O}$ were purchased from Shanghai Aladdin Bio-Chem Technology Co., Ltd (China). Poly(lactic acid) (PLA) (4032D, $\left.M_{\mathrm{w}}=207 \mathrm{kDa}\right)$ was purchased from Nature Works LLC (Blair, NE, USA). Trichloromethane (analytical purity) was purchased from Xilong Scientific Co., Ltd (Shantou, China).

\subsection{Preparation of $L D H s @ P A-C u(I I)$}

Generally, $\mathrm{MgAl}-\mathrm{CO}_{3} \mathrm{LDHs}(0.0500 \mathrm{~g})$ was dispersed in deionized water $(100 \mathrm{~mL})$ under ultrasonic treatment for $0.5 \mathrm{~h}$. Furthermore, PA aqueous solution $(0.0500 \mathrm{~g}, 0.053 \mathrm{mmol}$ PA) was added into $\mathrm{MgAl}-\mathrm{CO}_{3} \mathrm{LDHs}$ dispersion. Then, the dispersion was kept magnetic stirring for $15 \mathrm{~min}$ to achieve the purpose of adsorption. Subsequently, $\mathrm{CuCl}_{2} \cdot 2 \mathrm{H}_{2} \mathrm{O}(0.0090 \mathrm{~g}, 0.053 \mathrm{mmol})$ was added into the above dispersion under continuous stirring for $2 \mathrm{~h}$. The color of the above dispersion gradually changed to light blue. The product (LDHs@PA-Cu(II)) was obtained by centrifugation, washing and finally drying.

\subsection{Preparation of LDHs@PA-Cu(II)/PLA Nanocomposites}

According to data in Table 1, a certain amount of LDHs@PA-Cu(II) was dispersed in trichloromethane under ultrasonic treatment for $0.5 \mathrm{~h}$. Subsequently, PLA was added to LDHs@PA-Cu(II) dispersion at room temperature under continuous stirring for $4 \mathrm{~h}$. Then, the dispersion was treated with ultrasonic for $15 \mathrm{~min}$. Subsequently, the above dispersion was vaporized to obtain composite films in the horizontal polytetrafluoroethylene molds at room temperature. For comparison, the same processing was used for preparing $\mathrm{MgAl}-\mathrm{CO}_{3} \mathrm{LDHs} / \mathrm{PLA}$ nanocomposites (named as LDHs/PLA, $\mathrm{MgAl}-\mathrm{CO}_{3} \mathrm{LDHs}$ loading was $\left.1 \mathrm{wt} \%\right)$. 
Table 1. Composition of LDHs@PA-Cu(II)/PLA nanocomposites.

\begin{tabular}{cccc}
\hline Sample & PLA/g & LDHs@PA-Cu(II)/g & LDHs@PA-Cu(II)/wt \% \\
\hline PLA & 1.4 & 0 & 0 \\
LPCP0.5 & 1.4 & 0.0070 & 0.5 \\
LPCP1 & 1.4 & 0.0140 & 1 \\
LPCP3 & 1.4 & 0.0433 & 3 \\
LPCP5 & 1.4 & 0.0737 & 5 \\
\hline
\end{tabular}

\subsection{Characterization}

\subsubsection{Fourier Transforms Infrared Spectroscopy Analysis}

Fourier transform infrared spectroscopy (FT-IR) spectra were recorded by a spectrophotometer (ALPHA, Bruker, Billerica, MA, USA) in the region of $400-4000 \mathrm{~cm}^{-1}$ with resolution $4 \mathrm{~cm}^{-1}$ for 64 scans. The samples were mixed and ground with $\mathrm{KBr}$ and then pressed to pellets.

\subsubsection{X-ray Diffraction Analysis}

X-ray diffraction (XRD) analysis was performed on a powder diffractometer ( $\mathrm{X}^{\prime}$ pert, Panalytical, Almelo, the Netherlands), using CuK $\alpha$ radiation (1.5406 $\AA$ ) at a scanning rate of $5^{\circ} / \mathrm{min}$ (from $5^{\circ}$ to $80^{\circ}$ ).

\subsubsection{Microstructure and Elemental Analysis}

The surface micromorphology of the samples was observed by scanning electron microscope (SEM) (sigma500, Zeiss, Oberkochen, Germany) and transmission electron microscope (TEM) (Talos, FEI, Eindhoven, the Netherlands), respectively. For the analysis of fracture surface, the samples were fractured in liquid nitrogen and then coated with gold. Furthermore, chemical elemental analysis of the samples was performed on energy-dispersive X-ray spectrometry (EDS) (X-Max ${ }^{\mathrm{n}}$, Oxford, Abingdon, UK).

\subsubsection{Differential Scanning Calorimeter Analysis}

Thermal analysis was performed on a differential scanning calorimeter (DSC) (DSC214, Netzsch, Selb, Germany). The samples were measured in the temperature range from $-30{ }^{\circ} \mathrm{C}$ to $220{ }^{\circ} \mathrm{C}$ with heating and cooling rates of $10^{\circ} \mathrm{C} / \mathrm{min}$ using nitrogen as protection gas. The following expression was used to calculate crystallinity degree $(\chi)$ of PLA, $\chi=\left[\Delta H_{\mathrm{m}} /\left(\Delta H_{0} \times \varphi\right)\right] \times 100 \%$, where $\Delta H_{\mathrm{m}}$ and $\Delta H_{0}$ were the measured melting enthalpy and the melting enthalpy of $100 \%$ crystalline PLA (93.7 J/g) [3], and $\varphi$ was the mass fraction of PLA.

\subsubsection{Thermal Stability Analysis}

Thermal stability analysis was performed on a thermal gravimetric analyzer (TGA) (TG209F3, Netzsch, Selb, Germany). The samples were prepared in alumina pans and heated from 30 to $800{ }^{\circ} \mathrm{C}$ in nitrogen atmosphere at a heating rate of $10^{\circ} \mathrm{C} / \mathrm{min}$. The mass of the samples was $\sim 10 \mathrm{mg}$.

\subsubsection{Mechanical Property Analysis}

Mechanical measurements were carried out on a universal testing machine (ETM502B-Ex, Wance, Shenzhen, China). Mechanical properties were measured at a constant speed of $20 \mathrm{~mm} / \mathrm{min}$ in general accordance with ISO 527. At least five replicates for each type of the samples were tested.

\subsubsection{Oxygen Permeability Analysis}

Oxygen permeability was investigated using an oxygen permeability tester (OX-TRAN 2/21, Mocon, Minneapolis, MN, USA) according to ASTM D3985 at $23{ }^{\circ} \mathrm{C}$ and $0 \%$ RH. Oxygen permeability measurements were conducted on circular films $\left(5 \mathrm{~cm}^{2}\right)$. 


\subsubsection{Antibacterial Activity Analysis}

Antibacterial properties of the samples were investigated using shake flask method against Escherichia coli [21]. In order to obtain bacteria suspension, E. coli was cultured in Luria Broth (LB) solid medium for $24 \mathrm{~h}$ at $37^{\circ} \mathrm{C}$. A representative colony was cultured in LB liquid medium, followed by being incubated with shaking for $24 \mathrm{~h}$ at $37^{\circ} \mathrm{C}$. Bacterial cell concentration was estimated by measuring the absorbance of bacteria suspension. The bacteria suspension was diluted until the absorbance value of $600 \mathrm{~nm}$ was 0.1 . The absorbance value was recorded using a UV-visible spectrophotometer (SPECORD 210 PLUS, Analytikjena, Jena, Germany). In total, $150 \mu \mathrm{L}$ of bacterial solution was dropped into a conical flask containing $15 \mathrm{~mL}$ of liquid medium. Films (diameter $=1 \mathrm{~cm}$ ) and powders (mass $=50 \mathrm{mg}$ ), were dipped into falcon tubes containing the above bacterial solution, respectively. After shaking vigorously in a shaking incubator for $24 \mathrm{~h}$ at $37^{\circ} \mathrm{C}$, each diluent was spread onto the agar plate. Finally, viable microbial colonies were counted after incubating the plate for $24 \mathrm{~h}$ at $37^{\circ} \mathrm{C}$. The unit of value obtained by the method is colony-forming units $(\mathrm{CFU}) / \mathrm{cm}^{2}$. Furthermore, the antibacterial activity of the samples was evaluated by the antibacterial rate, which was equal to [(control value - sample value)/control value] $\times 100 \%$ [22].

\section{Results and Discussion}

\subsection{Chemical Structure of $\mathrm{MgAl}-\mathrm{CO}_{3} \mathrm{LDHs}$ and $\mathrm{LDHs} @ P A-C u(I I)$}

FT-IR spectra of MgAl-CO ${ }_{3}$ LDHs and LDHs@PA-Cu(II) are shown in Figure 1. FT-IR spectra of $\mathrm{MgAl}-\mathrm{CO}_{3}$ LDHs and LDHs@PA-Cu(II) show almost identical characteristics of typical LDHs. The infrared absorption peak of $\mathrm{MgAl}-\mathrm{CO}_{3} \mathrm{LDHs}$ at $3396 \mathrm{~cm}^{-1}$ is attributed to characteristic stretching vibration of hydroxyl groups and water molecules between layers. Affected strongly by hydroxyl groups of PA, the infrared absorption peak of LDHs@PA-Cu(II) is transferred to $3272 \mathrm{~cm}^{-1}$ [23]. Furthermore, the infrared absorption peak at $1352 \mathrm{~cm}^{-1}$ for $\mathrm{MgAl}-\mathrm{CO}_{3} \mathrm{LDHs}$ and LDHs@PA-Cu(II) is attributed to the vibrations of $\mathrm{CO}_{3}{ }^{2-}$ in the interlayer [17]. Compared with $\mathrm{MgAl}-\mathrm{CO}_{3} \mathrm{LDHs}$, LDHs@PA-Cu(II) shows new peaks at 1669, 1090 and $992 \mathrm{~cm}^{-1}$, which attributed to phosphate hydrogen radical $\left(\mathrm{HPO}_{4}{ }^{2-}\right)$, phosphate radical $\left(\mathrm{PO}_{4}{ }^{3-}\right)$, and $\mathrm{P}-\mathrm{O}-\mathrm{C}$ bonds in PA [20]. In addition, the infrared absorption peaks recorded below $700 \mathrm{~cm}^{-1}$ correspond to the vibration of metal-oxygen bonds in the $\mathrm{MgAl}-\mathrm{CO}_{3} \mathrm{LDHs}$ [15]. It is preliminary evidence that PA-Cu(II) coatings are synthesized on the $\mathrm{MgAl}-\mathrm{CO}_{3} \mathrm{LDHs}$.

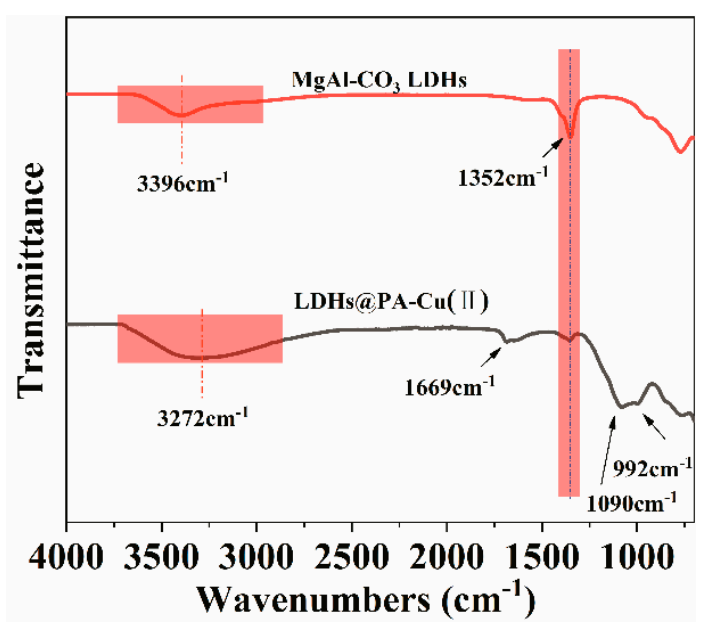

Figure 1. FT-IR spectra of MgAl-CO ${ }_{3}$ LDHs and LDHs@PA-Cu(II).

\subsection{Microstructure of $\mathrm{MgAl}-\mathrm{CO}_{3} \mathrm{LDHs}$ and LDHs@PA-Cu(II)}

SEM images of $\mathrm{MgAl}-\mathrm{CO}_{3} \mathrm{LDHs}$ and LDHs@PA-Cu(II) under different magnifications are shown in Figure 2. The synthetic MgAl-CO 3 LDHs and LDHs@PA-Cu(II) both clearly display a typical 
hexagonal layered structure, with a uniform size in $~ 1500 \mathrm{~nm}$. Meanwhile, compared with $\mathrm{MgAl}_{\mathrm{A}} \mathrm{CO}_{3}$ LDHs, the micromorphology of LDHs@PA-Cu(II) is more rough and mellow (as shown in Figure 2b).

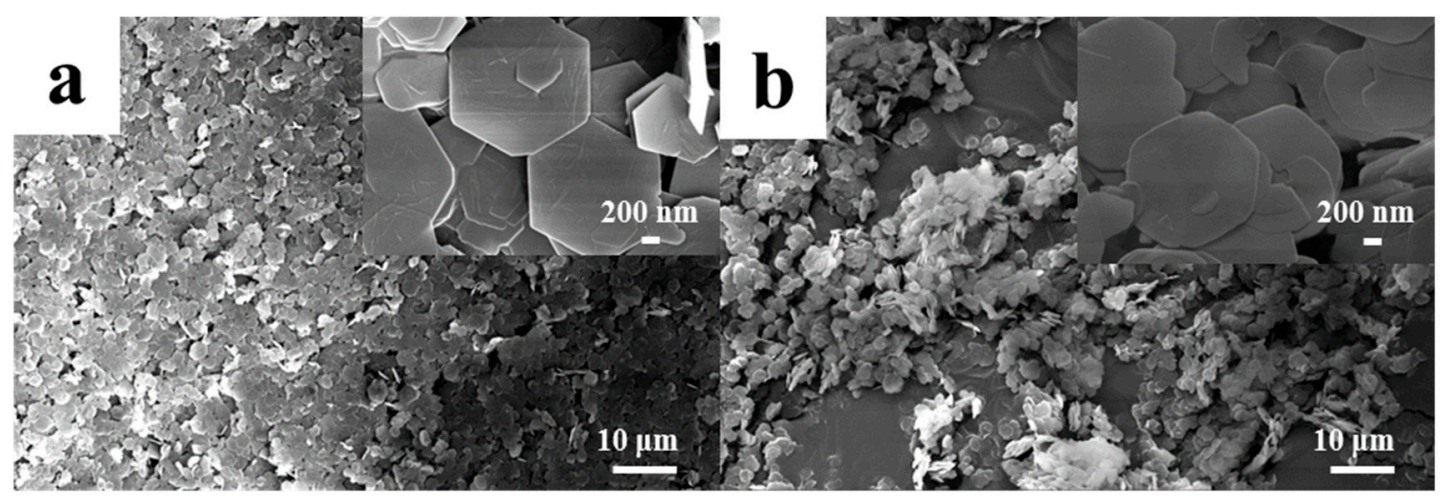

Figure 2. SEM images of (a) $\mathrm{MgAl}-\mathrm{CO}_{3} \mathrm{LDHs}$ and (b) LDHs@PA-Cu(II) under different magnifications.

Upon coating of PA-Cu(II) onto MgAl-CO $\mathrm{CO}_{3}$ LDHs, micromorphology of LDHs@PA-Cu(II) is further analyzed by TEM. As shown in Figure 3, it is revealed that $\mathrm{MgAl}-\mathrm{CO}_{3} \mathrm{LDH}$ are successfully coated by PA-Cu(II) coordination compounds. Furthermore, the thickness of PA-Cu(II) coatings is $\sim 8 \mathrm{~nm}$. It can be estimated from Figure 3b,c that the thickness of $\mathrm{MgAl}-\mathrm{CO}_{3}$ LDHs and LDHs@PA-Cu(II) are $40 \mathrm{~nm}$ and $\sim 56 \mathrm{~nm}$, respectively. As a result, the aspect ratio of them are $\sim 37.5$ and $\sim 26.8$, respectively. The aspect ratio will be used for the calculation of gas relative permeability discussed later [24,25].

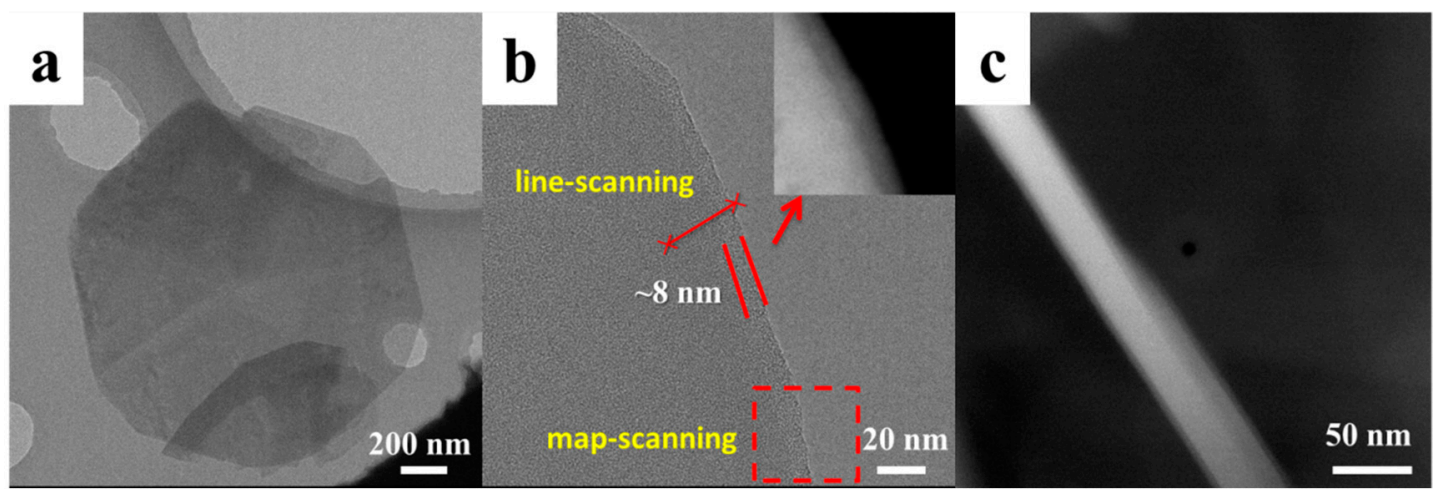

Figure 3. TEM images of (a,b) LDHs@PA-Cu(II) under different magnifications, and (c) $\mathrm{MgAl}-\mathrm{CO}_{3}$ LDHs from the lateral view.

In order to obtain evidence of PA- $\mathrm{Cu}(\mathrm{II})$ coordination compounds on the surface of $\mathrm{MgAl}-\mathrm{CO}_{3}$ LDHs directly, surface chemical elements are also analyzed by EDS (as shown in Figure 4). The related element analysis region is indicated in Figure $3 b$. In Figure $4 a, b$, the large peak for phosphorus indicates the existence of PA. The small peaks for copper indicate the existence of $\mathrm{Cu}$ (II) [26]. Furthermore, the uniform distribution of these elements reveals the uniformity of PA-Cu(II) coatings. In Figure 4c, EDS line-scanning reveals that the content of magnesium decrease sharply to the edge of LDHs@PA-Cu(II). Instead, the content of copper has little change, which further indicate the presence of PA-Cu(II) coordination compounds. 

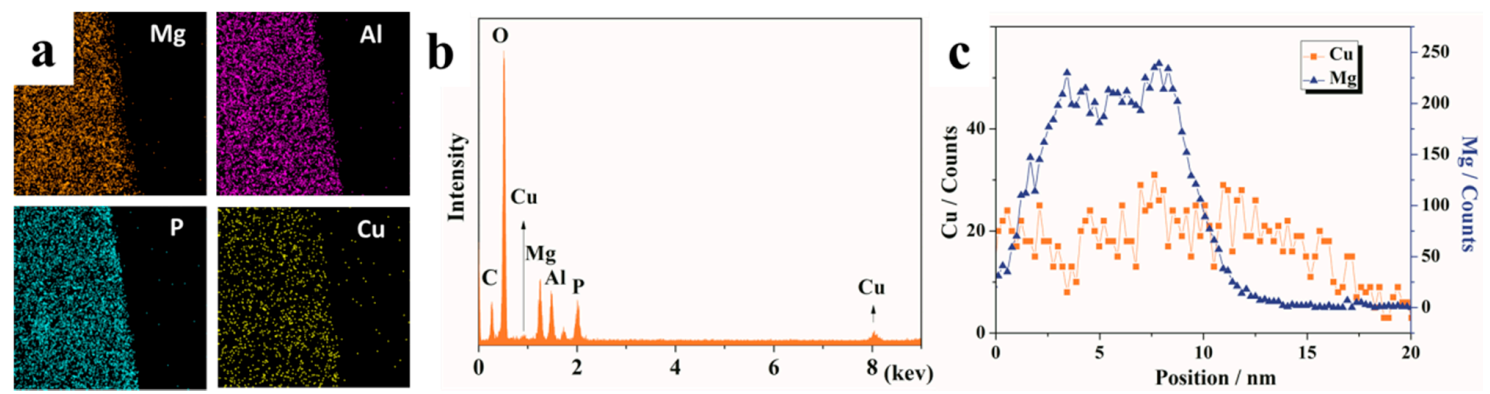

Figure 4. (a) EDS map-scanning of LDHs@PA-Cu(II), (b) EDS spectrum of LDHs@PA-Cu(II), (c) EDS line-scanning of LDHs@PA-Cu(II).

\subsection{Antibacterial Properties of LDHs@PA-Cu(II) and LDHs@PA-Cu(II)/PLA Nanocomposites}

In order to quantitatively evaluate the antibacterial properties of LDHs@PA-Cu(II) and LDHs@PA-Cu(II)/PLA nanocomposites, bacterial colony counter was used to count the number of colonies in the petri dishes with different samples. Furthermore, the antibacterial activity of the samples was evaluated by the antibacterial rate, as shown in Figure 5. In Figure 5, original $\mathrm{MgAl}-\mathrm{CO}_{3} \mathrm{LDHs}$ still shows a certain degree of antibacterial activity, and the antibacterial rate reaches $42.31 \%$. Upon coating of PA-Cu(II) onto $\mathrm{MgAl}-\mathrm{CO}_{3} \mathrm{LDHs}$, the antibacterial activity of LDHs@PA-Cu(II) is significantly improved, and the antibacterial rate is up to $99.99 \%$. Generally known, copper ion is effectively applied to inhibit bacterial growth in our life and production [27]. However, copper salt used alone is difficult to maintain a sustainable and uniform density of copper ions $[27,28]$. Therefore, LDHs@PA-Cu(II) can be a novel antibacterial agent to effectively inhibit bacterial growth and solve the problems associated with the direct addition of copper salt. The antibacterial properties of nanocomposites were improved by adding antibacterial nanoparticles. In Figure $5 b$, not surprisingly, $\mathrm{MgAl}-\mathrm{CO}_{3} \mathrm{LDHs}$ does not improve the antibacterial properties of PLA matrix. Furthermore, the antibacterial rate of LPCP1 and LPCP3 both exceeds $99.99 \%$. With the increase of LDHs@PA-Cu(II), the antibacterial properties of LDHs@PA-Cu(II)/PLA nanocomposites become more and more excellent.
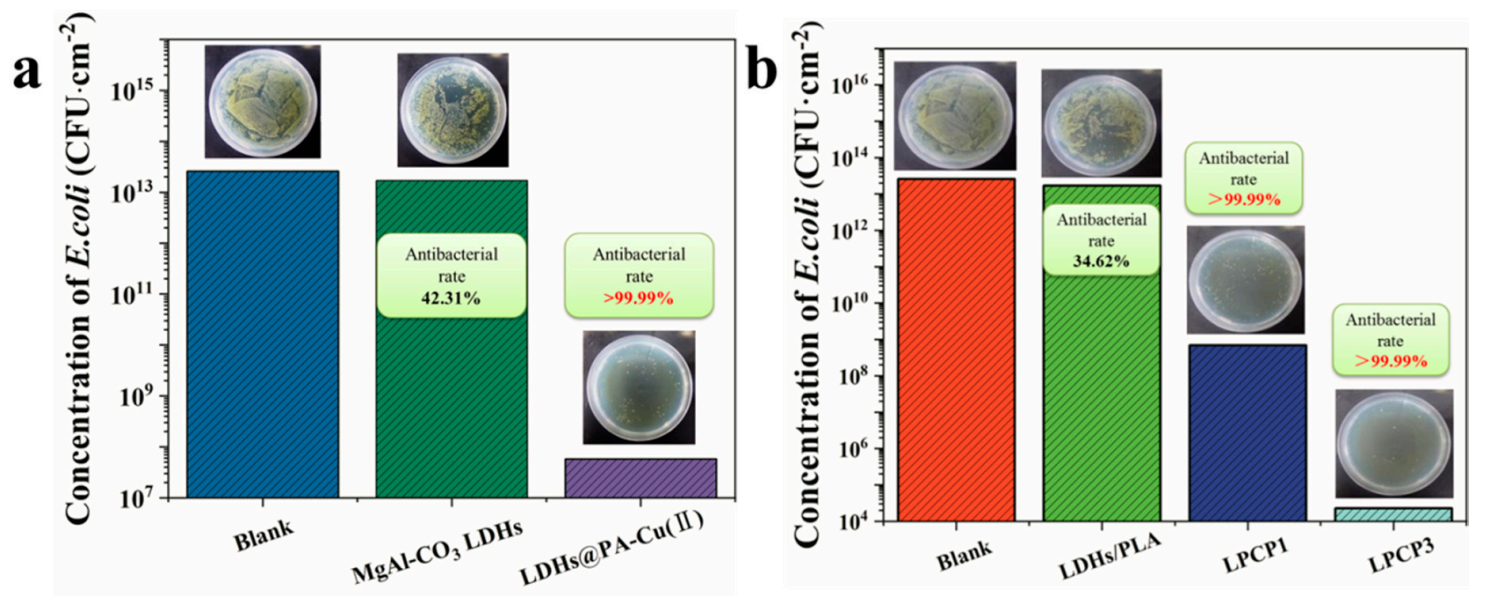
Figure 5.
Antibacterial properties
LDHs@PA-Cu(II)/PLA nanocomposites.

\begin{abstract}
(a) LDHs@PA-Cu(II) and
(b)
\end{abstract}
of

\subsection{Thermal Stability Properties of LDHs@PA-Cu(II) and LDHs@PA-Cu(II)/PLA Nanocomposites}

TGA curves of $\mathrm{MgAl}-\mathrm{CO}_{3}$ LDHs and LDHs@PA-Cu(II) are shown in Figure 6a. $\mathrm{MgAl}-\mathrm{CO}_{3}$ LDHs and LDHs@PA-Cu(II) exhibit similar two mass loss stages, which can be attributed to thermal decomposition characteristics of typical LDHs in nitrogen atmosphere. For $\mathrm{MgAl}-\mathrm{CO}_{3} \mathrm{LDHs}$, in the first stage of mass loss, the removal of absorbed water and crystalline water (moisture content $\sim 12 \%$ ) occur from room temperature to $\sim 215^{\circ} \mathrm{C}$. Furthermore, in the second stage of mass loss, dehydroxylation of 
lattice and thermal decomposition of carbonate ions in the interlayer occur from $\sim 215-\sim 575{ }^{\circ} \mathrm{C}$ [29]. In addition to mass loss characteristics of $\mathrm{MgAl}-\mathrm{CO}_{3}$ LDHs, mass loss of LDHs@PA-Cu(II) also includes the decomposition of PA-Cu(II) coatings. The results show that the thermal stability of LDHs@PA-Cu(II) is not deteriorated significantly.
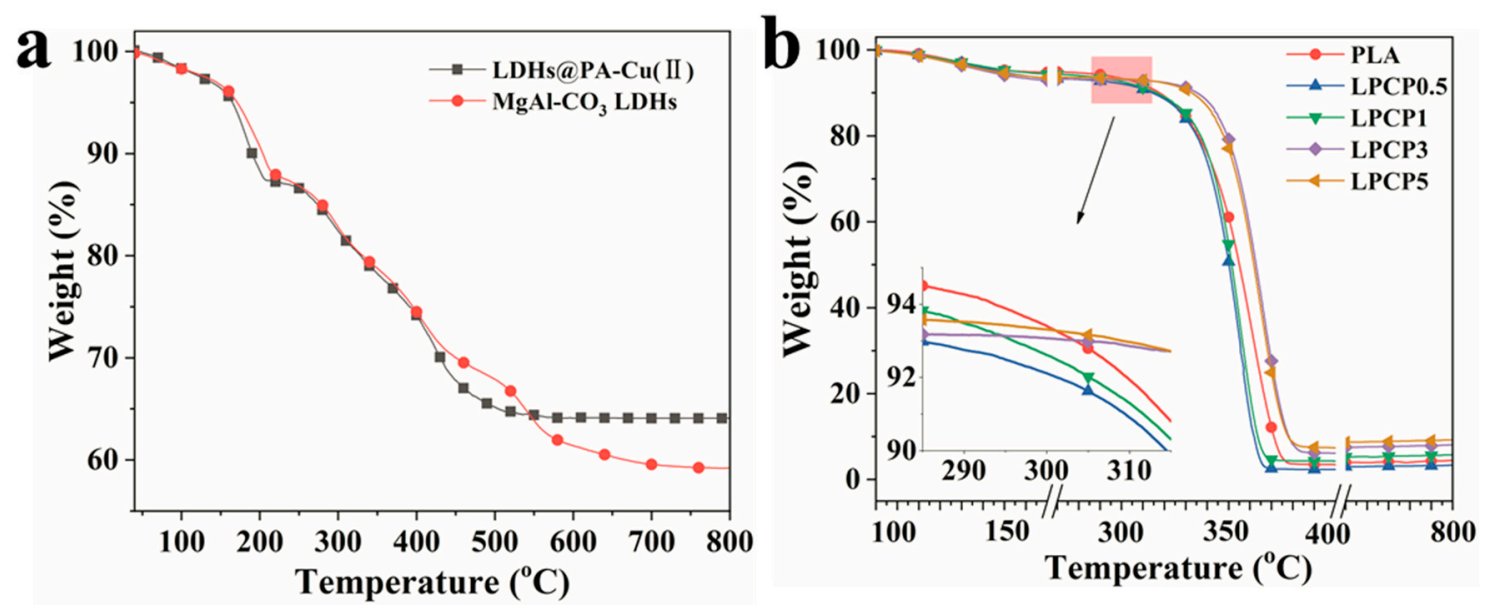

Figure 6. TGA curves of (a) LDHs@PA-Cu(II) and (b) LDHs@PA-Cu(II)/PLA nanocomposites.

TGA curves of LDHs@PA-Cu(II)/PLA nanocomposites are shown in Figure 6b. According to previous research [30,31], the addition of unmodified LDHs or phosphonium-modified LDHs in the PLA matrix leads to an obvious decrease in the thermal stability of PLA matrix. When the addition of LDHs@PA-Cu(II) increases from 0 to 1 wt \%, the thermal stability of LDHs@PA-Cu(II)/PLA nanocomposites has the similar trend. Interestingly, this is not yet the case when the addition of LDHs@PA-Cu(II) exceeds 1 wt \%. This phenomenon can be explained by the barrier effect of LDHs@PA-Cu(II) when the addition of LDHs@PA-Cu(II) reaches a certain level [32]. LDHs@PA-Cu(II) reduces the initial thermal stability of LDHs@PA-Cu(II)/PLA nanocomposites. However, the overall thermal stability of LDHs@PA-Cu(II)/PLA nanocomposites is improved gradually with the increase of LDHs@PA-Cu(II).

\subsection{Thermal and Crystallization Properties of LDHs@PA-Cu(II)/PLA Nanocomposites}

To investigate the effect of LDHs@PA-Cu(II) on the thermal properties of PLA matrix, DSC analysis was performed and DSC second heating curves are shown in Figure 7a. The corresponding data of thermal analysis, such as glass transition temperature $\left(T_{\mathrm{g}}\right)$, melting temperature $\left(T_{\mathrm{m}}\right)$, melting enthalpy $\left(\Delta H_{\mathrm{m}}\right)$ and crystallinity $(\chi)$, are presented in Table 2. As shown in Figure 7a and Table $2, T_{\mathrm{g}}$ of PLA is observed to be $60.3^{\circ} \mathrm{C}$, while that of LDHs@PA-Cu(II)/PLA nanocomposites increases slightly. This can be attributed to stronger interaction of PA-Cu(II) coatings to change the mobility of PLA chains related to the glass transition [33]. The calculated $\chi$ of LDHs@PA-Cu(II)/PLA nanocomposites are much higher than that of pure PLA as LDHs@PA-Cu(II) content increases, demonstrating the nucleating effect induced by LDHs@PA-Cu(II). Furthermore, $T_{\mathrm{m}}$ of LDHs@PA-Cu(II)/PLA nanocomposites show a slight increase compared with that of pure PLA. All the nanocomposites show one melting peak at 166.0 167.5 ${ }^{\circ} \mathrm{C}$ from the second heating scan. 

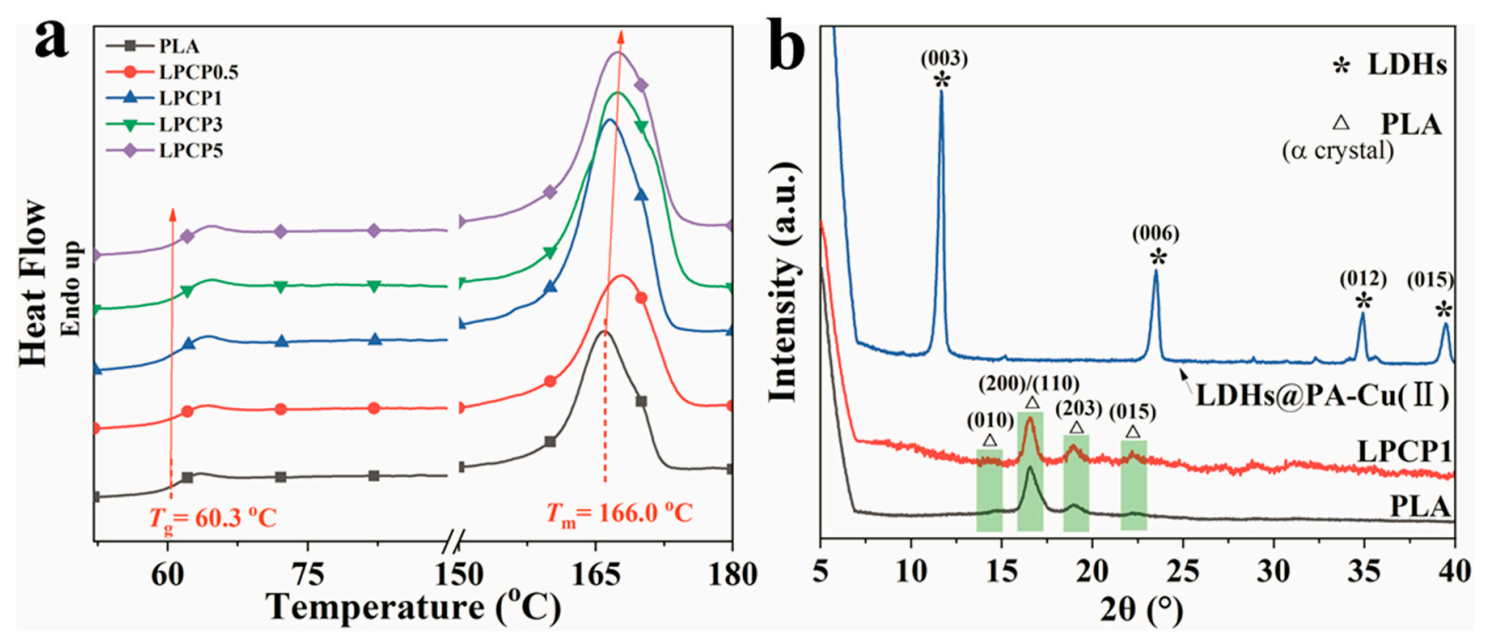

Figure 7. (a) DSC second heating curves and (b) XRD patterns of LDHs@PA-Cu(II)/PLA nanocomposites and LDHs@PA-Cu(II).

The $\alpha$-form crystals are exclusively formed in both pure PLA and LDHs@PA-Cu(II)/PLA nanocomposites, as evidenced by the XRD patterns given in Figure $7 \mathrm{~b}$. It is noteworthy that the presence of LDHs@PA-Cu(II) has no effect on the crystalline form of PLA. XRD patterns of PLA and LPCP1 exhibit reflections at $2 \theta=14.67^{\circ}, 16.68^{\circ}, 18.99^{\circ}$, and $22.39^{\circ}$, corresponding to $(010),(200) /(110)$, (203) and (015) planes of the typical orthorhombic crystal form for PLA matrix [33,34]. After the addition of 1 wt \% LDHs@PA-Cu(II), the diffraction peak intensity of LPCP1 increased to a certain extent. This is consistent with DSC analysis results. However, there is no visible characteristic diffraction peak (003) of typical LDHs in the LPCP1, which may be due to the low content and diffraction peak intensity of LDHs@PA-Cu(II) [5].

Table 2. The related results of LDHs@PA-Cu(II)/PLA nanocomposites according to thermal analysis.

\begin{tabular}{ccccc}
\hline Sample & $\boldsymbol{T}_{\mathrm{g}} /{ }^{\circ} \mathbf{C}$ & $\boldsymbol{T}_{\mathrm{m}} /{ }^{\circ} \mathbf{C}$ & $\Delta \boldsymbol{H} / \mathbf{J} \cdot \mathbf{g}^{-\mathbf{1}}$ & $\chi / \%$ \\
\hline PLA & 60.3 & 166.0 & 32.31 & 34.5 \\
LPCP0.5 & 60.9 & 167.8 & 36.59 & 39.2 \\
LPCP1 & 60.5 & 166.6 & 50.83 & 54.8 \\
LPCP3 & 61.2 & 167.4 & 48.45 & 53.3 \\
LPCP5 & 60.9 & 167.5 & 45.91 & 51.6 \\
\hline
\end{tabular}

\subsection{Mechanical Properties and Microstructure of LDHs@PA-Cu(II)/PLA Nanocomposites}

Mechanical properties of LDHs@PA-Cu(II)/PLA nanocomposites are shown in Figure 8. Compared with pure PLA, LPCP1 shows a 53.0\% increase in elongation at break and a $18.9 \%$ increase in tensile strength when adding 1 wt \% LDHs@PA-Cu(II). According to previous research, the increase of heterogeneous nucleation and interfacial interaction can improve the toughness of material [7]. Furthermore, tensile strength of LDHs@PA-Cu(II)/PLA nanocomposites are continuing to increase when LDHs@PA-Cu(II) content is no more than 1 wt \%. The improvement of tensile strength can be attributed to the good adhesion between LDHs@PA-Cu(II) and PLA matrix, which hinders the chains movement and restricts the deformation ability, eventually results in reinforcing effect which increases the resistance to the external mechanical forces [3]. When LDHs@PA-Cu(II) content exceeds $1 \mathrm{wt} \%$, tensile strength and elongation at break of LDHs@PA-Cu(II)/PLA nanocomposites begin to decrease gradually. Nonetheless, when the addition of LDHs@PA-Cu(II) reaches $5 \mathrm{wt} \%$, mechanical properties of LDHs@PA-Cu(II)/PLA nanocomposites is still better than those of pure PLA. As a general rule, except for the change of filler content, the strength of composites also depends on the size and distribution of defects in the composites, and the size and distribution of defects finally determine the loading degree of composites before failure [35]. Good interface interaction can effectively reduce 
interface defects in the composites. Therefore, it is noteworthy that mechanical properties of PLA can be improved noticeably by adding appropriate amount of LDHs@PA-Cu(II).

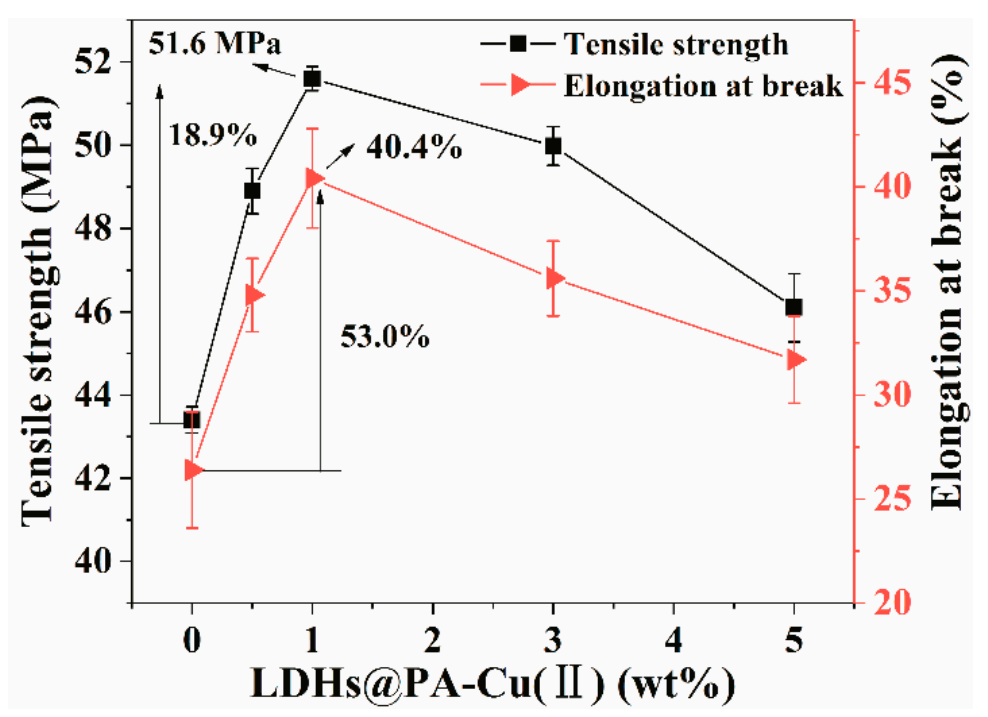

Figure 8. Mechanical properties of LDHs@PA-Cu(II)/PLA nanocomposites.

In order to further understand the relationship between interfacial structure and mechanical properties, SEM was employed to analyze the fracture surface of LDHs@PA-Cu(II)/PLA nanocomposites, as shown in Figure 9. According to previous research $[5,36]$, overall fracture surface of pure PLA is rough, which indicates plastic deformation. Figure $9 \mathrm{a}, \mathrm{b}$ both show rough and well stretched surface (a large number of curled broken fibrils), indicating LDHs@PA-Cu(II) can improve the flexibility of PLA matrix [37-39]. As shown in Figure 9c, LDHs@PA-Cu(II) tightly combines with PLA matrix without visible interface gap. Furthermore, LDHs@PA-Cu(II) (1 wt \%) is uniformly distributed in PLA matrix with a small amount of aggregates. Generally, relatively good dispersion of nanoparticles can be achieved in the nanocomposites with low nanoparticles content [5]. In Figure 9d, apparently, LDHs@PA-Cu(II) (5 wt \%) shows much more heterogeneous dispersion with apparent agglomerates, which indicates that the interfacial compatibility and dispersibility of LDHs@PA-Cu(II) get worse [6]. To some extent, this can explain the reasons for the change of mechanical properties with LDHs@PA-Cu(II) contents increase. Meanwhile, the better interfacial bonding, the fewer the interfacial defects, which is also closely related to the better gas barrier properties of materials [17]. 


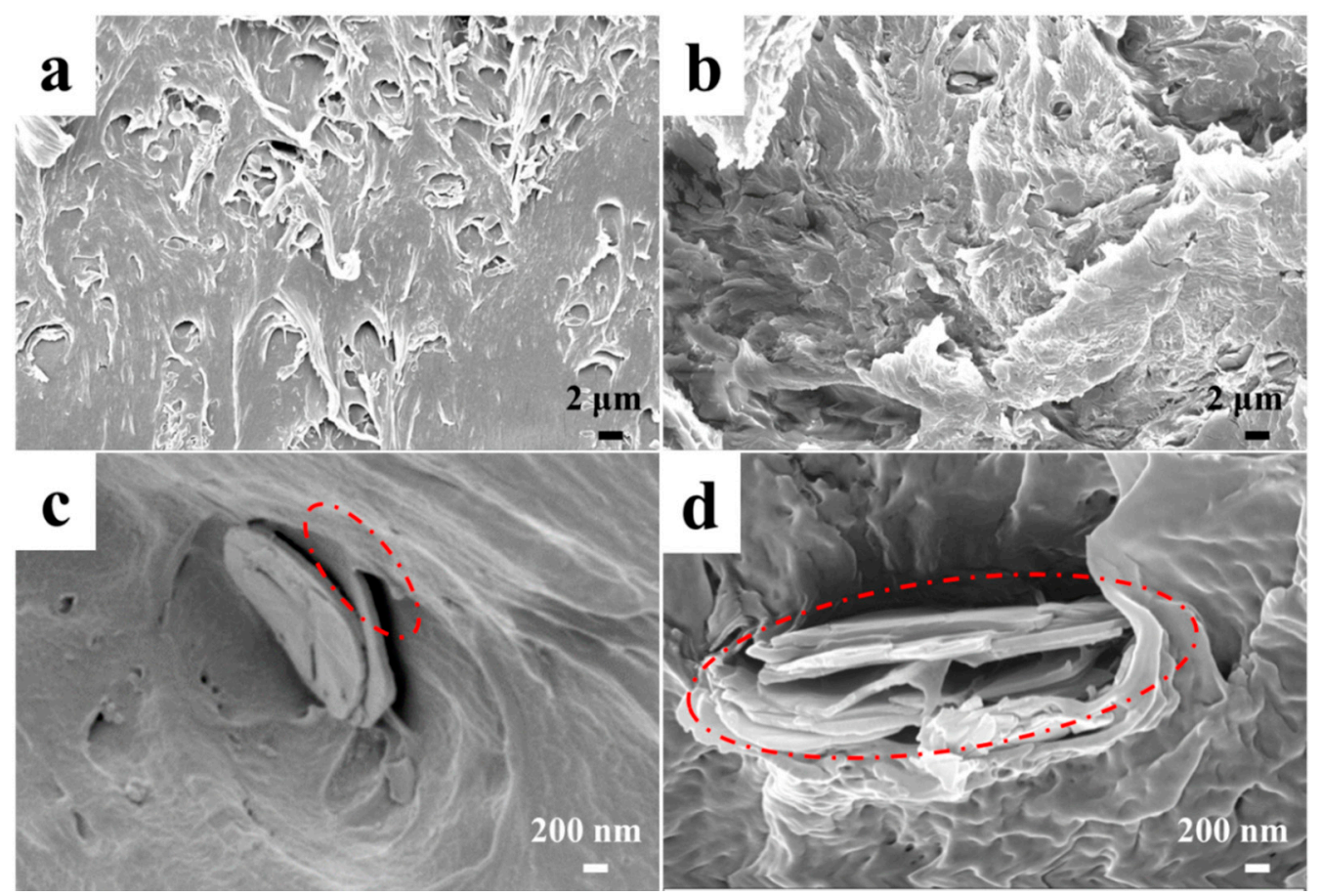

Figure 9. SEM images of fracture surface for LDHs@PA-Cu(II)/PLA nanocomposites with 1 wt \% LDHs@PA-Cu(II) (a,c) and 5 wt \% LDHs@PA-Cu(II) (b,d).

\subsection{Oxygen Barrier Properties and Mechanism of LDHs@PA-Cu(II)/PLA Nanocomposites}

Oxygen permeability of LDHs@PA-Cu(II)/PLA nanocomposites is shown in Figure 10. When LDHs@PA-Cu(II) content reaches $1 \mathrm{wt} \%, R_{\mathrm{p}}$ (relative permeability $=\mathrm{P} / \mathrm{P}_{0}$ ) is decreased obviously to $72.0 \%$, thereafter it slowly decreases. Only when LDHs@PA-Cu(II) is better dispersed in PLA matrix and the interface is stronger between clay and PLA matrix can this be achieved, which contributes to the reduced interface defects and tortuous path of gas diffusion $[40,41] . R_{\mathrm{p}}$ of LDHs@PA-Cu(II)/PLA nanocomposites decreases by only $20.9 \%$ as LDHs@PA-Cu(II) content increases from $1 \mathrm{wt} \%$ to $5 \mathrm{wt} \%$. This reflects a significant reduction in barrier efficiency of LDHs@PA-Cu(II). Therefore, PA-Cu(II) coatings play an important role in reducing gas permeability in LDHs@PA-Cu(II)/PLA nanocomposites.

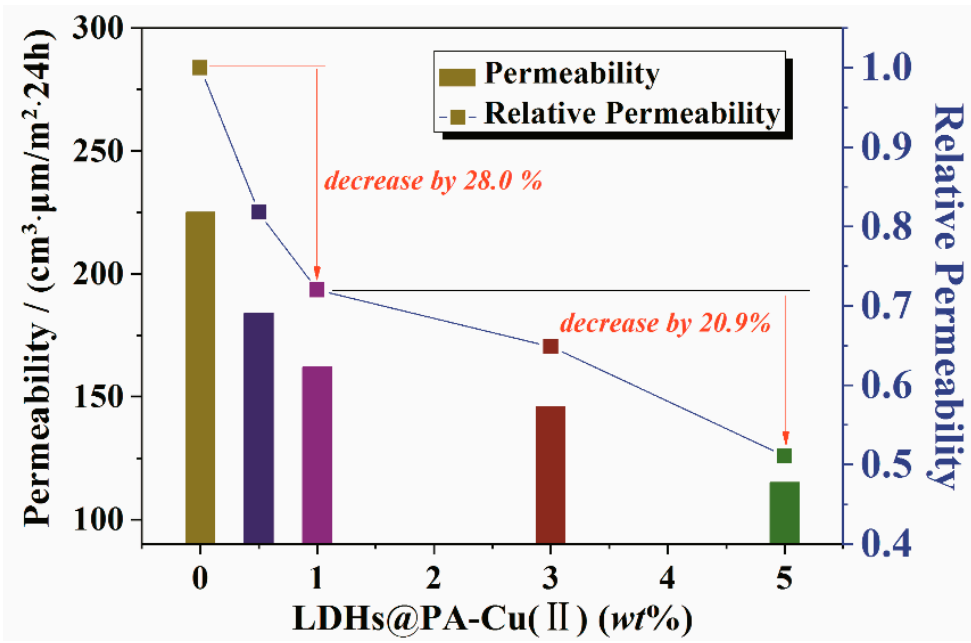

Figure 10. $\mathrm{O}_{2}$ permeability of LDHs@PA-Cu(II)/PLA nanocomposites and pure PLA.

According to considerable reports in the literature [42-44], the barrier mechanism of layered clay is mainly related to the bulk effect and barrier effect. As a rule, layered clay/polymer nanocomposites are 
composed of a permeable phase (polymer matrix) and an impermeable phase (layered clay). The bulk effect of layered clay can hinder the dissolution of gas molecules in the composite films. The barrier effect of layered clay can prevent permeation of the gas molecules through the composite films.

Nielsen's detour theory was first proposed, and has been used to predict the $R_{\mathrm{p}}$ of filled polymer composites. So far, many permeability prediction models are still optimized based on this theory [45]. Based on Nielsen's detour theory, classical relative permeability equation can be expressed as follows,

$$
R_{p}=\frac{\left(1-\varnothing_{s}\right)}{1+\frac{L}{2 W} \varnothing_{s}}
$$

where $L, W$, and $\phi_{\mathrm{s}}$ represent the volume fraction, diameter and thickness of LDHs@PA-Cu(II), respectively. The aspect ratio $(L / W, \sim 26.8)$ has been calculated in the previous analysis.

According to the relative permeability equation, experimental values and the predicted of $R_{\mathrm{p}}$ can be calculated as shown in Figure 11. The results show that $R_{\mathrm{p}}$ of the experimental values is significantly lower than that of the predicted values. Furthermore, the deviation $(0.14 \sim 0.20)$ between experimental and predicted values is large in the whole region. The reason is that Nielsen's model is based on geometric analysis entirely. Two important factors are not considered in this model: the effect of layered clay on the structure of polymer matrix (such as crystallization) and the interface interaction [45]. The interfacial incompatibility can lead to the formation of interface defects and eventually the increase of gas permeability. Considering our layered clay/polymer nanocomposites, the introduction of LDHs@PA-Cu(II) can cause interaction of different types toward PLA matrix, resulting in more strong interaction interface $[40,46]$.

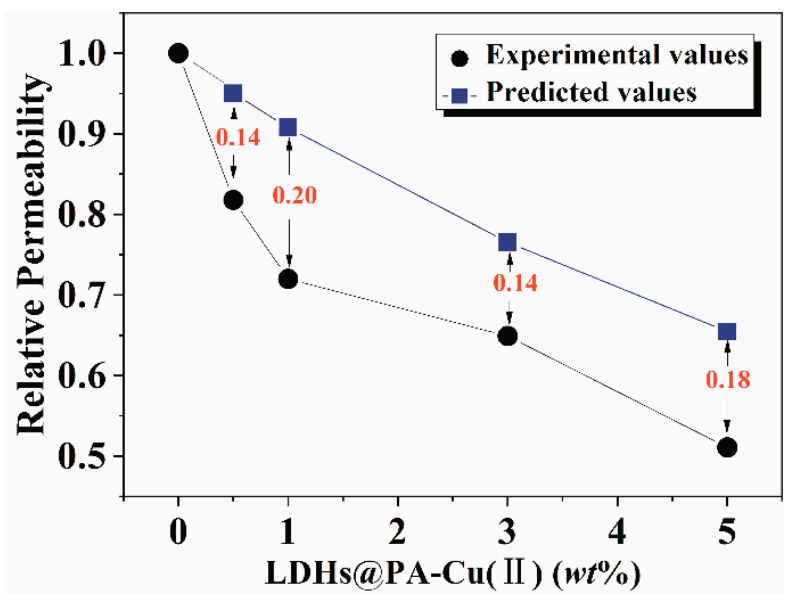

Figure 11. Relative permeability for experimental and predicted values.

\section{Conclusions}

LDHs@PA-Cu(II) was firstly synthetized via facile deposition and chelation of PA-Cu(II) coordination compounds on the surface of LDHs. Furthermore, LDHs@PA-Cu(II)/PLA nanocomposites were prepared by blending LDHs@PA-Cu(II) and pure PLA via solution casting evaporation process. It is revealed that PA-Cu(II) coordination compounds are uniformly coated on $\mathrm{MgAl}-\mathrm{CO}_{3} \mathrm{LDHs}_{\text {at }}$ a thickness of $\sim 8 \mathrm{~nm}$. With this nanoscale coatings, the mechanical, and gas barrier properties of LDHs@PA-Cu(II)/PLA nanocomposites are improved significantly, which are attributed to strong interface interaction and heterogenous nucleation. After adding only 1 wt \% LDHs@PA-Cu(II), elongation at break and tensile strength increase by $53.0 \%$ and $18.9 \%$ respectively, and the oxygen relative permeability decreases by $28.0 \%$. However, excess addition of LDHs@PA-Cu(II) lead to the decrease of mechanical properties. Nonetheless, elongation at break and tensile strength of LDHs@PA-Cu(II)/PLA nanocomposites are both higher than those of pure PLA. The analysis of barrier mechanism reveals that the important factors for improving the barrier properties are 
not only the bulk effect and barrier effect of LDHs@PA-Cu(II), but also the specific interactions between LDHs@PA-Cu(II) and PLA matrix. Meanwhile, due to the antibacterial activity of PA-Cu(II) coatings, the antibacterial rate of LDHs@PA-Cu(II) exceeds 99.99\%. Furthermore, the corresponding LDHs@PA-Cu(II)/PLA nanocomposites also shows outstanding antibacterial properties. Therefore, antibacterial LDHs@PA-Cu(II)/PLA nanocomposites have broad application prospects in active packaging due to their biodegradability and physical properties.

Author Contributions: Conceptualization, L.M. and Y.L.; methodology, Y.L.; software, L.M. and Y.L.; validation, Z.L.; formal analysis, J.Y.; investigation, Y.L.; resources, L.M. and J.Y.; data curation, Y.L.; writing-original draft preparation, Y.L. and L.M.; writing-review and editing, J.Y.; visualization, L.M. and J.Y.; supervision, Y.L.; project administration, L.M.; funding acquisition, L.M. and J.Y. All authors have read and agreed to the published version of the manuscript.

Funding: This research was funded by National Natural Science Foundation of China (No. 11872179), Science and Technology Planning Project of Fujian Province, China (No. 2018H6024), Natural Science Foundation of Hunan province, China (No. 2019JJ50132), High-Level Talents Support Plan of Xiamen University of Technology, China (No. YKJ19008R), The scientific research project of Hunan Province Education Department, China (No. 19K027).

Conflicts of Interest: The authors declare no conflicts of interest.

\section{References}

1. Zhou, X.; Yang, R.; Wang, B.; Chen, K. Development and characterization of bilayer films based on pea starch/polylactic acid and use in the cherry tomatoes packaging. Carbohyd. Polym. 2019, 222, 114912-114919. [CrossRef] [PubMed]

2. Kim, I.; Viswanathan, K.; Kasi, G.; Sadeghi, K.; Thanakkasaranee, S.; Seo, J. Poly(Lactic Acid)/ZnO Bionanocomposite Films with Positively Charged $\mathrm{ZnO}$ as Potential Antimicrobial Food Packaging Materials. Polymers 2019, 11, 1427. [CrossRef] [PubMed]

3. Patwa, R.; Kumar, A.; Katiyar, V. Effect of silk nano-disc dispersion on mechanical, thermal, and barrier properties of poly(lactic acid) based bionanocomposites. J. Appl. Polym. Sci. 2018, 135, 46671-46682. [CrossRef]

4. Hamad, K.; Kaseem, M.; Ayyoob, M.; Joo, J.; Deri, F. Polylactic acid blends: The future of green, light and tough. Prog. Polym. Sci. 2018, 85, 83-127. [CrossRef]

5. Huang, H.; Ren, P.; Xu, J.; Xu, L.; Zhong, G.; Hsiao, B.S.; Li, Z. Improved barrier properties of poly(lactic acid) with randomly dispersed graphene oxide nanosheets. J. Membr. Sci. 2014, 464, 110-118. [CrossRef]

6. Sullivan, E.M.; Karimineghlani, P.; Naraghi, M.; Gerhardt, R.A.; Kalaitzidou, K. The effect of nanofiller geometry and compounding method on polylactic acid nanocomposite films. Eur. Polym. J. 2016, 77, 31-42. [CrossRef]

7. Sung, S.H.; Chang, Y.; Han, J. Development of polylactic acid nanocomposite films reinforced with cellulose nanocrystals derived from coffee silverskin. Carbohyd. Polym. 2017, 169, 495-503. [CrossRef]

8. Zhang, Y.; Liu, Q.; Zhang, S.; Zhang, Y.; Cheng, H. Gas barrier properties and mechanism of kaolin/styrene-butadiene rubber nanocomposites. Appl. Clay Sci. 2015, 111, 37-43. [CrossRef]

9. Adak, B.; Butola, B.S.; Joshi, M. Effect of organoclay-type and clay-polyurethane interaction chemistry for tuning the morphology, gas barrier and mechanical properties of clay/polyurethane nanocomposites. Appl. Clay Sci. 2018, 161, 343-353. [CrossRef]

10. Choudalakis, G.; Gotsis, A.D. Permeability of polymer/clay nanocomposites: A review. Eur. Polym. J. 2009, 45, 967-984. [CrossRef]

11. Tammaro, L.; Costantino, U.; Bolognese, A.; Sammartino, G.; Marenzi, G.; Calignano, A.; Tetè, S.; Mastrangelo, F.; Califano, L.; Vittoria, V. Nanohybrids for controlled antibiotic release in topical applications. Int. J. Antimicrob. Ag. 2007, 29, 417-423. [CrossRef] [PubMed]

12. Pucciariello, R.; Tammaro, L.; Villani, V.; Vittoria, V. New nanohybrids of poly( $\varepsilon$-caprolactone) and a modified $\mathrm{Mg} / \mathrm{Al}$ hydrotalcite: Mechanical and thermal properties. J. Polym. Sci. Pol. Phys. 2007, 45, 945-954. [CrossRef]

13. Gonçalves, N.A.; Caio, T.R.N.; de Moraes, S.B.; Lona, L.M.F. Synthesis and characterization of biodegradable poly(l-lactide)/layered double hydroxide nanocomposites. Polym. Bull. 2014, 71, 2235-2245. [CrossRef]

14. Katiyar, V.; Gerds, N.; Koch, C.B.; Risbo, J.; Hansen, H.C.B.; Plackett, D. Poly l-lactide-layered double hydroxide nanocomposites via in situ polymerization of l-lactide. Polym. Degrad. Stabil. 2010, 95, $2563-2573$. [CrossRef] 
15. Mao, L.; Wu, H.; Liu, Y.; Yao, J.; Bai, Y. Enhanced mechanical and gas barrier properties of poly( $\varepsilon$-caprolactone) nanocomposites filled with tannic acid-Fe(III) functionalized high aspect ratio layered double hydroxides. Mater. Chem. Phys. 2018, 211, 501-509. [CrossRef]

16. Mao, L.; Liu, Y.; Bai, Y.; Wu, H.; Liu, X. Poly( $\varepsilon$-caprolactone) nanocomposites with layered double hydroxides modified by in situ grafting polymerization: Structure characterization and barrier properties. J. Appl. Polym. Sci. 2017, 134, 45320-45326. [CrossRef]

17. Mao, L.; Liu, Y.; Wu, H.; Chen, J.; Yao, J. Poly( $\varepsilon$-caprolactone) filled with polydopamine-coated high aspect ratio layered double hydroxide: Simultaneous enhancement of mechanical and barrier properties. Appl. Clay Sci. 2017, 150, 202-209. [CrossRef]

18. Liu, X.; Zhang, Q.; Cheng, B.; Ren, Y.; Zhang, Y.; Ding, C. Durable flame retardant cellulosic fibers modified with novel, facile and efficient phytic acid-based finishing agent. Cellulose 2018, 25, 799-811. [CrossRef]

19. Kalali, E.N.; Zhang, L.; Shabestari, M.E.; Croyal, J.; Wang, D. Flame-retardant wood polymer composites (WPCs) as potential fire safe bio-based materials for building products: Preparation, flammability and mechanical properties. Fire Saf. J. 2019, 107, 210-216. [CrossRef]

20. Wang, D.; Xu, F.; Hu, J.; Lin, M. Phytic acid/graphene oxide nanocomposites modified electrode for electrochemical sensing of dopamine. Mat. Sci. Eng. C Mater. 2017, 71, 1086-1089. [CrossRef]

21. Kim, H.J.; Kim, D.; Yoon, H.; Choi, Y.; Yoon, J.; Lee, J. Polyphenol/FeIII complex coated membranes having multifunctional properties prepared by a one-step fast assembly. Adv. Mater. Interfaces 2015, 2, 1500298-1500305. [CrossRef]

22. Bumbudsanpharoke, N.; Lee, W.; Ko, S. A comprehensive feasibility study on the properties of LDPE-Ag nanocomposites for food packaging applications. Polym. Composite. 2018, 39, 3178-3186. [CrossRef]

23. Dai, H.; Wang, N.; Wang, D.; Ma, H.; Lin, M. An electrochemical sensor based on phytic acid functionalized polypyrrole/graphene oxide nanocomposites for simultaneous determination of $\mathrm{Cd}(\mathrm{II})$ and $\mathrm{Pb}(\mathrm{II})$. Chem. Eng. J. 2016, 299, 150-155. [CrossRef]

24. Tao, Q.; Zhang, Y.; Zhang, X.; Yuan, P.; He, H. Synthesis and characterization of layered double hydroxides with a high aspect ratio. J. Solid State Chem. 2006, 179, 708-715. [CrossRef]

25. Gursky, J.A.; Blough, S.D.; Luna, C.; Gomez, C.; Luevano, A.N.; Gardner, E.A. Particle-particle interactions between layered double hydroxide nanoparticles. J. Am. Chem. Soc. 2006, 128, 8376-8377. [CrossRef] [PubMed]

26. Kim, H.J.; Im, S.; Kim, J.C.; Hong, W.G.; Shin, K.; Jeong, H.Y.; Hong, Y.J. Phytic Acid Doped Polyaniline Nanofibers for Enhanced Aqueous Copper(II) Adsorption Capability. ACS Sustain. Chem. Eng. 2017, 5, 6654-6664. [CrossRef]

27. Hu, C.H.; Xu, Z.R.; Xia, M.S. Antibacterial effect of Cu2+-exchanged montmorillonite on Aeromonas hydrophila and discussion on its mechanism. Vet. Microbiol. 2005, 109, 83-88. [CrossRef]

28. Rosu, T.; Negoiu, M.; Pasculescu, S.; Pahontu, E.; Poirier, D.; Gulea, A. Metal-based biologically active agents: Synthesis, characterization, antibacterial and antileukemia activity evaluation of $\mathrm{Cu}(\mathrm{II}), \mathrm{V}(\mathrm{IV})$ and $\mathrm{Ni}(\mathrm{II})$ complexes with antipyrine-derived compounds. Eur. J. Med. Chem. 2010, 45, 774-781. [CrossRef]

29. Liu, Y.; Mao, L.; Fan, S. Preparation and study of intumescent flame retardant poly(butylene succinate) using MgAlZnFe-CO3 layered double hydroxide as a synergistic agent. J. Appl. Polym. Sci. 2014, 131, 8964-8973. [CrossRef]

30. Livi, S.; Bugatti, V.; Estevez, L.; Duchet-Rumeau, J.; Giannelis, E.P. Synthesis and physical properties of new layered double hydroxides based on ionic liquids: Application to a polylactide matrix. J. Colloid Interf. Sci. 2012, 388, 123-129. [CrossRef]

31. Koh, H.C.; Park, J.S.; Jeong, M.A.; Hwang, H.Y.; Hong, Y.T.; Ha, S.Y.; Nam, S.Y. Preparation and gas permeation properties of biodegradable polymer/layered silicate nanocomposite membranes. Desalination 2008, 233, 201-209. [CrossRef]

32. Hule, R.A.; Pochan, D.J. Polymer nanocomposites for biomedical applications. Mrs Bull. 2007, 32, 354-358. [CrossRef]

33. Bai, H.; Huang, C.; Xiu, H.; Zhang, Q.; Deng, H.; Wang, K.; Chen, F.; Fu, Q. Significantly Improving Oxygen Barrier Properties of Polylactide via Constructing Parallel-Aligned Shish-Kebab-Like Crystals with Well-Interlocked Boundaries. Biomacromolecules 2014, 15, 1507-1514. [CrossRef] [PubMed]

34. Oksman, K.; Skrifvars, M.; Selin, J.F. Natural fibres as reinforcement in polylactic acid (PLA) composites. Compos. Sci. Technol. 2003, 63, 1317-1324. [CrossRef] 
35. Moyo, L.; Makhado, E.; Sinha Ray, S. Anomalous impact strength for layered double hydroxide-palmitate/ poly(e-caprolactone) nanocomposites. J. Appl. Polym. Sci. 2014, 131, 41109-41118. [CrossRef]

36. Abdulkhani, A.; Hosseinzadeh, J.; Ashori, A.; Dadashi, S.; Takzare, Z. Preparation and characterization of modified cellulose nanofibers reinforced polylactic acid nanocomposite. Polym. Test. 2014, 35, 73-79. [CrossRef]

37. Bai, Y.; Mao, L.; Liu, Y. High temperature shape memory polyimide ionomer. J. Appl. Polym. Sci. 2016, 133, 43630-43637. [CrossRef]

38. Liau, C.P.; Ahmad, M.B.; Shameli, K.; Yunus, W.M.Z.W.; Ibrahim, N.A.; Zainuddin, N.; Then, Y.Y. Preparation and characterization of polyhydroxybutyrate/polycaprolactone/Mg-Al layered double hydroxide nanocomposites. Dig. J. Nanomater. Bios. 2014, 9, 71-82.

39. Du, P.; Xue, B.; Song, Y.; Lu, S.; Yu, J.; Zheng, Q. Fracture surface characteristics and impact properties of poly(butylene terephthalate). Polym. Bull. 2010, 64, 185-196. [CrossRef]

40. Wu, J.; Huang, G.; Li, H.; Wu, S.; Liu, Y.; Zheng, J. Enhanced mechanical and gas barrier properties of rubber nanocomposites with surface functionalized graphene oxide at low content. Polymer 2013, 54, 1930-1937. [CrossRef]

41. Carosio, F.; Colonna, S.; Fina, A.; Rydzek, G.; Hemmerl, J.; Jierry, L.C.; Schaaf, P.; Boulmedais, F. Efficient Gas and Water Vapor Barrier Properties of Thin Poly(lactic acid) Packaging Films: Functionalization with Moisture Resistant Nafion and Clay Multilayers. Chem. Mater. 2014, 26, 5459-5466. [CrossRef]

42. Bharadwaj, R.K. Modeling the barrier properties of polymer-layered silicate nanocomposites. Macromolecules 2001, 34, 9189-9192. [CrossRef]

43. Layek, R.K.; Das, A.K.; Park, M.J.; Kim, N.H.; Lee, J.H. Enhancement of physical, mechanical, and gas barrier properties in noncovalently functionalized graphene oxide/poly(vinylidene fluoride) composites. Carbon 2015, 81, 329-338. [CrossRef]

44. Xu, B.; Zheng, Q.; Song, Y.; Shangguan, Y. Calculating barrier properties of polymer/clay nanocomposites: Effects of clay layers. Polymer 2006, 47, 2904-2910. [CrossRef]

45. Gain, O.; Espuche, E.; Pollet, E.; Alexandre, M.; Dubois, P. Gas barrier properties of poly(e-caprolactone)/clay nanocomposites: Influence of the morphology and polymer/clay interactions. J. Polym. Sci. Pol. Phys. 2005, 34, 205-214. [CrossRef]

46. Genovese, L.; Gigli, M.; Lotti, N.; Gazzano, M.; Siracusa, V.; Munari, A.; Rosa, M.D. Biodegradable long chain aliphatic polyesters containing ether-linkages: Synthesis, solid-state, and barrier properties. Ind. Eng. Chem. Res. 2014, 53, 10965-10973. [CrossRef] 